\title{
Multiple Sclerosis in Older Adults: The Clinical Profile and Impact of Interferon Beta Treatment
}

\author{
Afsaneh Shirani, ${ }^{1}$ Yinshan Zhao, ${ }^{1}$ John Petkau, ${ }^{2}$ Paul Gustafson, ${ }^{2}$ \\ Mohammad Ehsanul Karim, ${ }^{2}$ Charity Evans, ${ }^{3}$ Elaine Kingwell, ${ }^{1}$ Mia L. van der Kop, ${ }^{1,4}$ \\ Joel Oger, ${ }^{1}$ and Helen Tremlett ${ }^{1}$ \\ ${ }^{1}$ Department of Medicine, Division of Neurology and Brain Research Centre, UBC Hospital, \\ University of British Columbia, 2211 Wesbrook Mall, Vancouver, BC, Canada V6T 2B5 \\ ${ }^{2}$ Department of Statistics, University of British Columbia, 3182 Earth Sciences Building, 2207 Main Mall, \\ Vancouver, BC, Canada V6T 1Z4 \\ ${ }^{3}$ College of Pharmacy and Nutrition, University of Saskatchewan, 110 Science Place, Saskatoon, SK, Canada S7N 5C9 \\ ${ }^{4}$ Department of Public Health Sciences, Karolinska Institutet, 17177 Stockholm, Sweden
}

Correspondence should be addressed to Helen Tremlett; helen.tremlett@ubc.ca

Received 5 September 2014; Revised 28 February 2015; Accepted 2 March 2015

Academic Editor: Eberval G. Figueiredo

Copyright (c) 2015 Afsaneh Shirani et al. This is an open access article distributed under the Creative Commons Attribution License, which permits unrestricted use, distribution, and reproduction in any medium, provided the original work is properly cited.

Background. We examined (1) patient characteristics and disease-modifying drug (DMD) exposure in late-onset (LOMS, $\geq 50$ years at symptom onset) versus adult-onset (AOMS, 18-<50 years) MS and (2) the association between interferon-beta (IFN $\beta$ ) and disability progression in older relapsing-onset MS adults ( $\geq 50$ years). Methods. This retrospective study (1980-2004, British Columbia, Canada) included 358 LOMS and 5627 AOMS patients. IFN $\beta$-treated relapsing-onset MS patients aged $\geq 50$ (regardless of onset age, 90) were compared with 171 contemporary and 106 historical controls. Times to EDSS 6 from onset and from IFN $\beta$ eligibility were examined using survival analyses. Results. LOMS patients (6\%) were more likely to be male, with motor onset and a primary-progressive course, and exhibit faster progression and were less likely to take DMDs. Nonetheless, 57\% were relapsingonset, of which $31 \%$ were prescribed DMDs, most commonly IFN $\beta$. Among older relapsing-onset MS adults, no significant association between IFN $\beta$ exposure and disability progression was found when either the contemporary (hazard ratio [HR]: 0.46; 95\% CI: 0.18-1.22) or historical controls (HR: 0.54; 95\% CI: 0.20-1.42) were considered. Conclusion. LOMS differed clinically from AOMS. One-third of older relapsing-onset MS patients were prescribed a DMD. IFN $\beta$ exposure was not significantly associated with reduced disability in older MS patients.

\section{Introduction}

Multiple sclerosis (MS) is a chronic degenerative disease of the central nervous system. It is said to be the most common cause of neurological disability in young adults in the Western world [1]; however, as life expectancy is only minimally affected [2], the impact of disability can be felt across a relatively long lifespan. Clinical symptoms characteristically first present in people in their mid-20s to 30s; however, a wide spectrum exists, and as the general population ages, the prevalence of MS in older adults rises [3]. Despite the average age of those living with MS in western countries having reached an all-time high (mid-50s) [3], relatively little is known about the clinical characteristics of "older" adults with MS or their use of and response to treatment.

While some previous studies have described the characteristics and/or prognosis of older MS patients [4-12], we were unable to find any studies examining exposure rates or response to disease-modifying drugs (DMDs) in these patients. Historically, older adults were actively excluded from internationally recognized diagnostic criteria for MS (e.g., Poser criteria) [13], as well as from clinical trials. For example, the most widely used DMDs for relapsing-onset MS were approved based on the pivotal clinical trials where the average age of patients was 35 and those over the age of 50 or 55 were excluded [14-16]. Therefore, there remains a need to 
better understand this understudied, older population with MS.

Here, we first describe the demographic and clinical characteristics, as well as the prescription patterns, of DMDs in patients with late-onset MS (LOMS) defined as symptoms onset after 50 years of age in comparison with adult-onset MS (AOMS) patients; and second we examine the association between exposure to interferon beta (IFN $\beta$ ) and disability progression in relapsing-onset MS patients aged $\geq 50$ (regardless of onset age) in the real-world setting in British Columbia (BC), Canada.

\section{Methods}

2.1. Design and Setting. We conducted a retrospective cohort study based on prospectively collected data in the British Columbia Multiple Sclerosis (BCMS) database. Established in 1980, the BCMS database is estimated to capture $80 \%$ of the British Columbian MS population $[17,18]$ and links the four MS clinics in BC over the study period (1980-2004). The database has been used extensively for research $[10,19-$ 21]. The study was approved by the University of British Columbia's Clinical Research Ethics Board, which includes informed patient consent.

2.2. Patients and Data. Patients had to be registered with a BCMS clinic between August 1980 and December 2004 and diagnosed with definite MS (based on Poser or McDonald criteria) [13, 22]. For aim 1, that is, description of those with LOMS versus AOMS, LOMS was defined as symptom onset at age of 50 or older and AOMS as symptom onset between 18 and $<50$ years of age. Clinical and demographic data, including onset symptoms, relapses in the first 5 years, disability (Expanded Disability Status Scale [EDSS]) at first clinic visit, and DMD exposure, were derived from the BCMS database, with follow-up until December 31, 2008. Onset symptoms were classified as motor, sensory, and optic neuropathy and cerebellar, ataxic, or brainstem (CAB) and initial disease course as relapsing versus primary progressive [23].

For aim 2, that is, investigation of the association between exposure to IFN $\beta$ and disability progression, older adults aged 50 or older at baseline, that is, at eligibility for IFN $\beta$ treatment (regardless of onset age), were potentially considered. This broader age criterion was specific to aim 2 to make the findings more clinically relevant to daily practice and to maximize the cohort size. IFN $\beta$ drugs were selected since they represent the most commonly used DMDs. IFN $\beta$ eligibility was broadly adapted [19] from the BC government's reimbursement scheme which required patients to have definite relapsing-onset $\mathrm{MS}$ and an EDSS score $\leq 6.5$. An EDSS score of 6.5 indicates the need for constant bilateral assistance to walk about 20 meters without resting [24]. Study baseline was defined as the first clinic visit following their 50th birthday at which a patient reached eligibility for IFN $\beta$ treatment between April 1985 and December 2004. April 1985 was the first date that health-related administrative data became available. These data were accessed to provide individual patient-level data on IFN $\beta$ prescription (through the province's comprehensive PharmaNet database) [25]; information on preexisting comorbidities (through hospital and community (physician visit) data, that is, the Hospital Separations Discharge Abstract [26] and Medical Service Plan Payment [27] data); and socioeconomic status (through Census Geodata and geocodes provided by the Medical Services Plan Registration \& Premium Billing file) [28]. Clinical data were linked with these health administrative data using each patient's unique personal health number, facilitated by Population Data BC (a panprovincial population health data resource). Patients were excluded if they had fewer than two prospective EDSS assessments from baseline or were enrolled in a clinical trial or exposed to DMDs prior to study baseline. From the population of eligible patients, three cohorts were selected: one treated cohort and two separate untreated control cohorts (one contemporary and one historical). The treated cohort included patients exposed to IFN $\beta$ who first became treatment eligible between July 1995 (when the first IFN $\beta$ was licensed for MS in Canada) and December 2004. The contemporary control cohort comprised patients who first became treatment eligible in the same period (July 1995December 2004) but who remained unexposed to IFN $\beta$. The historical control cohort included those first eligible prior to the approval of IFN $\beta$ (April 1985-June 1995) but who remained unexposed to IFN $\beta$ throughout the study period. Patients were followed until the last EDSS assessment prior to the study end date (December 31, 2008). Patients eligible for the current study would also have been included in a wider study examining the association of IFN $\beta$ exposure and disability progression in MS [19], but that study was not specifically designed to study IFN $\beta$ exposure in older adults with MS.

2.3. Exposure to IFN $\beta$ Treatment. To examine the association between exposure to IFN $\beta$ treatment and disability progression (aim 2), all IFN $\beta$ products were grouped together as one therapeutic class, including IFN $\beta$-1b [Betaseron, $250 \mu \mathrm{g}$ subcutaneously on alternate days] and IFN $\beta$-1a [Avonex, $30 \mu \mathrm{g}$ intramuscularly once weekly; and Rebif, $22 \mu \mathrm{g}$ or $44 \mu \mathrm{g}$ subcutaneously 3 times per week] [29]. Since $98 \%$ of exposed patients had either no break or a break of $<3$ months between consecutive administrations of IFN $\beta$ over the study period, product switches or breaks were not considered as treatment interruptions for these analyses.

2.4. Outcomes. The main disability outcome was time to a confirmed and sustained EDSS score of 6, from MS symptom onset (for aim 1) and from IFN $\beta$ eligibility date for aim 2. EDSS 6 indicates "intermittent or unilateral constant assistance (cane, crutch, and brace) required to walk about 100 meters with or without resting" [24]. EDSS 6 was defined as "confirmed" when a subsequent score of $\geq 6$ at least 150 days later was recorded and "sustained" when all subsequent EDSS scores were $\geq 6$. The secondary outcome for aim 2 was time from baseline to a confirmed and sustained score of 4 . An EDSS score of 4 indicates being "fully ambulatory without aid, up and about 12 hours a day despite relatively severe disability; able to walk without aid 500 meters" [24]. 
2.5. Statistical Analyses. For aim 1, demographic and clinical characteristics and DMD prescription patterns for the LOMS versus AOMS cohorts were compared using the Pearson $\chi^{2}$ test for categorical variables and the $t$-test for continuous variables. The Kaplan-Meier survival curves and the logrank test were used to compare time from MS onset to confirmed and sustained EDSS 6. The independent effect of potential risk factors on time to reach EDSS 6 was examined using a multivariable Cox regression model, with sex, onset symptoms, and onset age category (AOMS versus LOMS), with relapsing-onset and primary-progressive MS patients examined separately. Two sensitivity analyses were conducted. Firstly, patients with an unknown time to EDSS 6 (because EDSS 6 had already been reached at the first clinic visit) were included by imputing the midway time between MS onset and the first clinic assessment. Secondly, data were censored once a DMD was initiated.

For aim 2, similar bivariate statistics were used when comparing the baseline characteristics of the IFN $\beta$-treated versus contemporary and historical untreated cohorts, along with the Mann-Whitney-Wilcoxon test for ordinal variables. The Kaplan-Meier survival curves were used to estimate the proportion of patients reaching the main outcome within 10 years of study baseline. Multivariable Cox proportional hazards regression models were used to assess the hazard of reaching EDSS 6 and 4, with IFN $\beta$ exposure as a timedependent predictor (to minimize immortal time bias) [30]. By considering exposure to IFN $\beta$ as a binary time-dependent variable, we were able to adjust for changes in treatment status. More specifically, the value of this binary predictor changed according to the patient's treatment status at each event time and thus accounted for the unexposed time from baseline to initiation of IFN $\beta$, the actual IFN $\beta$-exposed time, and the unexposed time between stopping IFN $\beta$ and the end of follow-up. The main model was also adjusted for sex, age, disease duration, and EDSS score at baseline in all analyses. Additional model adjustments included annualized relapse rate (based on the two years prior to baseline) and, for the contemporary approach only, socioeconomic status and preexisting comorbidities (because of data availability). The proportional hazard assumption was assessed using loglog plots. Results were expressed as hazard ratios with 95\% confidence intervals (CI).

All statistical tests were 2 -sided, and $P<0.05$ was considered statistically significant. Statistical analyses were conducted using the Statistical Package for the Social Sciences (SPSS Inc. Chicago, Illinois, version 16.0).

\section{Results}

For aim 1, 5985 patients were included, 358 (6\%) with LOMS and 5627 (94\%) with AOMS. Patient characteristics (clinical and demographic) are shown in Table 1. Those with LOMS were more likely to be male, present with motor or $\mathrm{CAB}$ symptoms, and have a primary-progressive course at onset, whereas they were less likely to present with sensory or optic neuropathy symptoms compared to AOMS patients. Exposure to MS drugs was less common in LOMS patients
(19.6\% versus $38.1 \%$ for AOMS), although a reasonable proportion of relapsing-onset LOMS patients were exposed (30.6\% versus $41.0 \%$ of those with AOMS).

Patients with either relapsing-onset or primary-progressive LOMS (versus AOMS) progressed more rapidly from onset to EDSS 6 (Supplementary Figure e-1 in Supplementary Material available online at http://dx.doi.org/10.1155/2015/ 451912). After adjusting for sex and onset symptoms, the hazard of progression to EDSS 6 in the relapsing-onset cohort was 3.28 times higher (95\% CI: 2.34-4.62) for LOMS versus AOMS patients and 1.51 times higher (95\% CI: 0.99-2.31) in the primary-progressive cohort (although the 95\% CI included one); see Figure 1. Findings from the sensitivity analyses were in a similar direction to those observed in the main analyses (Figures e-2 to e-5).

For aim 2, a total of 367 patients were included (Figure 2). From these, 90 formed the IFN $\beta$-treated cohort, 171 formed the contemporary control cohort, and 106 formed the historical control cohort. Their baseline characteristics are shown in Table 2. The proportion of women in each cohort ranged from $70.2 \%$ to $81.1 \%$, with more women in the treated versus contemporary untreated cohort. The mean age at MS onset was similar between the three cohorts, ranging from 40.7 to 43.3 years. The mean baseline disease duration was shorter in the treated cohort $(10.9 \pm 10.7$ years $)$ compared to the untreated contemporary $(14.9 \pm 11.4$ years $)$ and historical $(15.1 \pm 12.1$ years $)$ cohorts; however the median baseline EDSS score was 2.5 in all the three cohorts.

Findings from the adjusted multivariable Cox regression model, with IFN $\beta$ exposure as a time-dependent covariate, are shown in Figure 3. We found no significant association between exposure to IFN $\beta$ treatment and time till progression to the main outcome, sustained and confirmed EDSS 6, when either of the contemporary or historical control cohorts was the comparison group (HR $=0.46,95 \%$ CI: $0.18-1.22$ for the contemporary approach [Figure 3(a)] and $\mathrm{HR}=0.54,95 \%$ CI: $0.20-1.42$ for the historical approach [Figure 3(b)]). In both approaches, a higher baseline EDSS was associated with a higher hazard of reaching EDSS 6. Adding the annualized relapse rate (based on the two years prior to baseline) to the model did not change findings in either the contemporary or historical approach ( $\mathrm{HR}=0.48,95 \% \mathrm{CI}: 0.18-1.26$ and $\mathrm{HR}=$ 0.51, 95\% CI: 0.19-1.33, resp.), nor did adding comorbidity or socioeconomic status (data not shown). The actual numbers of individuals that reached the main outcome were 10 (11.1\%), $22(12.9)$, and $31(29.2 \%)$ in the treated, contemporary control, and historical control cohorts, respectively. The estimated proportions of patients (from Kaplan-Meier curves) reaching the main outcome within 10 years of baseline were $31.1 \%$, $30.3 \%$, and $39.5 \%$, respectively. Findings were also similar when the secondary outcome (EDSS 4) was considered (see Figure e-6).

\section{Discussion}

In our cohort, over 1 in 16 adults with MS had symptom onset at or after 50 years of age. These patients differed clinically from those with AOMS. Consistent with other studies 
TABLE 1: Characteristics of patients with late-onset versus adult-onset MS, British Columbia, Canada [aim 1].

\begin{tabular}{|c|c|c|c|}
\hline Characteristics & Late-onset MS $(n=358)$ & Adult-onset MS $(n=5627)$ & $P$ value \\
\hline \multicolumn{4}{|l|}{ Sex, $n(\%)$} \\
\hline Male & $132(36.9)$ & $1550(27.5)$ & \multirow{2}{*}{$<0.001^{\prime}$} \\
\hline Female & $226(63.1)$ & $4077(72.5)$ & \\
\hline \multirow[t]{2}{*}{ Age at onset, mean $( \pm \mathrm{SD})$, median [range], years } & $55.4(4.9), 54.1[50.0-75.8]$ & 32.0 (8.0), 31.2 [18.0-49.99] & \multirow[t]{4}{*}{$<0.001$} \\
\hline & $50-<55$ yrs: $201(56.1)$ & $18-<30$ yrs: $2539(45.1)$ & \\
\hline \multirow[t]{2}{*}{$n(\%)$} & $55-<60$ yrs: $104(29.1)$ & $30-<40$ yrs: $2013(35.8)$ & \\
\hline & $\geq 60$ yrs: 53 (14.8) & $40-<50$ yrs: $1074(19.1)$ & \\
\hline \multicolumn{4}{|l|}{ Onset symptoms, $n(\%)$} \\
\hline \multicolumn{4}{|l|}{ Motor } \\
\hline Present & $140(39.1)$ & $1042(18.5)$ & \multirow{2}{*}{$<0.001^{\prime}$} \\
\hline Absent & $218(60.9)$ & $4585(81.5)$ & \\
\hline \multicolumn{4}{|l|}{ Sensory } \\
\hline Present & $107(29.9)$ & $2564(45.6)$ & \multirow{2}{*}{$<0.001^{\prime}$} \\
\hline Absent & $251(70.1)$ & $3063(54.4)$ & \\
\hline \multicolumn{4}{|l|}{ Optic neuropathy } \\
\hline Present & $20(5.6)$ & $949(16.9)$ & \multirow[t]{2}{*}{$<0.001^{\|}$} \\
\hline Absent & $338(94.4)$ & $4678(83.1)$ & \\
\hline \multicolumn{4}{|l|}{ Cerebellar, ataxia, or brainstem } \\
\hline Present & $71(19.8)$ & $849(15.1)$ & \multirow{2}{*}{$0.016^{\|}$} \\
\hline Absent & $287(80.2)$ & $4778(84.9)$ & \\
\hline \multicolumn{4}{|l|}{ Initial course, $n(\%)$} \\
\hline Relapsing & $206(57.5)$ & $5167(91.8)$ & \multirow{2}{*}{$<0.001^{\|}$} \\
\hline Primary-progressive & $152(42.5)$ & $460(8.2)$ & \\
\hline Age at first visit ${ }^{*}$, mean $( \pm S D)$, median [range], years & $60.5(6.4), 59.5[50.4-81.0]$ & $41.1(10.3), 40.7[18.4-80.9]$ & $<0.001^{9}$ \\
\hline Disease duration at first visit ${ }^{*}$, mean $( \pm \mathrm{SD})$, median [range], years & $5.2(4.7), 3.7[0.03-30.0]$ & $9.1(8.9), 6.2[0.0-59.2]$ & $<0.001^{9}$ \\
\hline Disease duration at last visit ${ }^{*}$, mean $( \pm S D)$, median [range], years & $10.2(5.7), 9.7[0.3-30.3]$ & $16.9(10.4), 15.1[0.00-60.2]$ & $<0.001^{9}$ \\
\hline Length of prospective follow-up time ${ }^{* \dagger}$, mean $( \pm S D)$, median [range], years & s $\quad 5.0(4.2), 4.1[0-19.3]$ & $7.8(6.5), 6.4[0-28.4]$ & $<0.001^{9}$ \\
\hline $\begin{array}{l}\text { Annualized relapse rate during the first five years after onset of symptoms }{ }^{\ddagger} \text {, } \\
\text { mean }( \pm S D) \text {, median [range] }\end{array}$ & $0.2(0.3), 0.2[0-1.8]$ & $0.3(0.4), 0.2[0-3.2]$ & $0.109^{9}$ \\
\hline \multicolumn{4}{|l|}{ Year of registration with the clinic, $n(\%)$} \\
\hline 1980-1985 & $51(14.2)$ & $979(17.4)$ & \\
\hline $1986-1990$ & $46(12.8)$ & $799(14.2)$ & \\
\hline 1991-1995 & $63(17.6)$ & $992(17.6)$ & $0.355^{\|}$ \\
\hline $1996-2000$ & $103(28.8)$ & $1568(27.9)$ & \\
\hline 2001-2004 & $95(26.5)$ & $1289(22.9)$ & \\
\hline \multicolumn{4}{|l|}{ Exposure to a "disease modifying drug" for MS, $n(\%)$} \\
\hline Ever & 70 (19.6) & $2143(38.1)$ & \multirow{2}{*}{$<0.001^{\mid}$} \\
\hline Never & $288(80.4)$ & $3484(61.9)$ & \\
\hline \multicolumn{4}{|l|}{$\begin{array}{l}\text { Exposure to a "disease modifying drug" for MS among patients with a } \\
\text { relapsing-onset course only, } n(\%)\end{array}$} \\
\hline Ever & $63(30.6)$ & $2120(41.0)$ & \multirow{2}{*}{$0.003^{\|}$} \\
\hline Never & $143(69.4)$ & $3047(59.0)$ & \\
\hline \multicolumn{4}{|l|}{$\begin{array}{l}\text { Initially prescribed drug among patients with a relapsing-onset } \\
\text { course only, } n(\%)\end{array}$} \\
\hline Interferon beta-1a (intramuscular) & $4(6.3)$ & $274(12.9)$ & \\
\hline Interferon beta-1a (subcutaneous) & $22(34.9)$ & $731(34.5)$ & \\
\hline
\end{tabular}


TABLE 1: Continued.

\begin{tabular}{|c|c|c|c|}
\hline Characteristics & Late-onset MS $(n=358)$ & Adult-onset MS $(n=5627)$ & $P$ value \\
\hline Interferon beta- $1 \mathrm{~b}$ (subcutaneous) & $24(38.1)$ & $755(35.6)$ & \\
\hline Glatiramer acetate & $11(17.5)$ & $254(12.0)$ & \\
\hline Natalizumab & $0(0)$ & $9(0.004)$ & \\
\hline Mitoxantrone & $1(1.6)$ & $43(2.0)$ & \\
\hline Others ${ }^{\S}$ & $1(1.6)$ & $54(2.5)$ & \\
\hline
\end{tabular}

EDSS, Expanded Disability Status Scale.

${ }^{*}$ Missing for 56 patients with adult-onset MS.

${ }^{\dagger}$ Time from first clinic visit to most recent clinic visit.

${ }^{\ddagger}$ Only reported for patients with relapsing-onset MS with at least 5 years of follow-up after the onset of symptoms including 4578 patients with adult-onset MS and 163 with late-onset MS.

${ }^{\S}$ Others included clinical trial drugs and cytotoxic immunosuppressants: teriflunomide (both cohorts) and in the adult-onset cohort, methotrexate, azathioprine, cyclophosphamide, FTY720 (fingolimod), cladribine, Hu23F2G (rovelizumab), lenercept, MBP8298 (dirucotide), NBI-5788, paclitaxel, and interferon alpha.

"Pearson's chi-square test.

'Student's $t$-test.

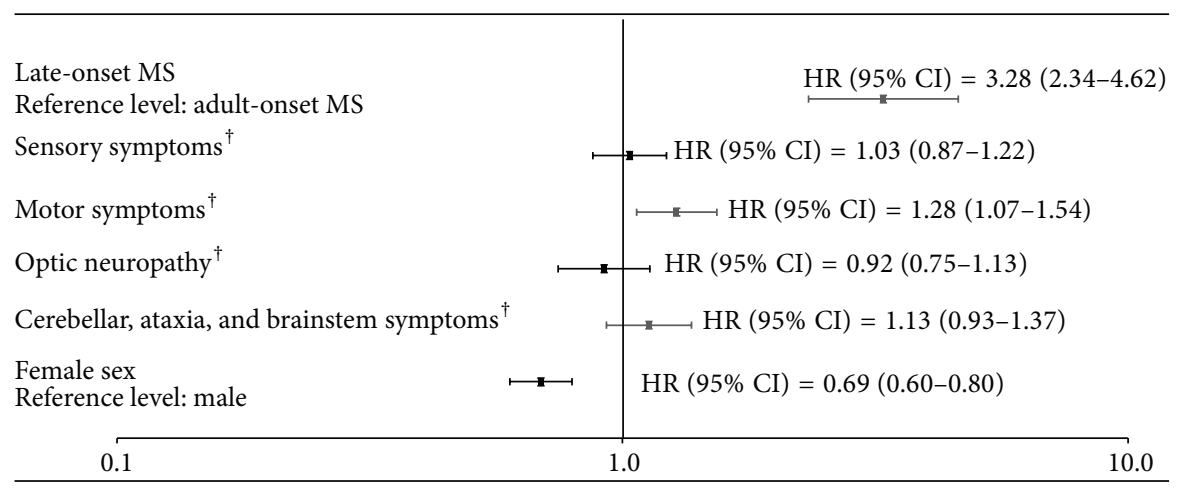

(a) Relapsing-onset MS patients $(n=4499)^{*}$

$\begin{aligned} & \text { Late-onset MS } \\ & \text { Reference level: adult-onset MS } \\ & \text { Sensory symptoms }{ }^{\dagger}\end{aligned}$
$\begin{aligned} & \text { Motor symptoms }{ }^{\dagger} \\ & \text { Optic neuropathy }\end{aligned}$
$\begin{aligned} & \text { Cerebellar, ataxia, and brainstem symptoms } \\ & \text { Female sex }\end{aligned}$
$\begin{aligned} & \text { Reference level: male } \\ & 0.1\end{aligned}$

(b) Primary-progressive MS patients $(n=339)^{\ddagger}$

FIGURE 1: Multivariable Cox regression analysis of potential factors associated with time to reach confirmed and sustained EDSS 6 from onset of MS symptoms in patients with relapsing-onset (a) and primary-progressive (b) MS. * Out of 5373 patients with relapsing-onset MS, 874 patients did not contribute to the analysis (i.e., were excluded from the analyses). Those included 640 patients who had already reached the outcome by first clinic assessment (i.e., were left-censored), 185 patients with no EDSS score recorded, and 49 patients who were censored before the earliest event. ${ }^{\dagger}$ Reference level = absence of the specific onset symptom. ${ }^{\ddagger}$ Out of 612 patients with primary-progressive MS, 273 patients did not contribute to the analysis (including 234 patients who had already reached the outcome by first clinic assessment (i.e., leftcensored), 33 patients with no EDSS score recorded, and 6 patients who were censored before the earliest event).

$[6,10-12]$, there were proportionally more men with motor onset symptoms and a primary-progressive course in the LOMS (versus AOMS) cohort. However, unlike some other studies $[6,10]$, we still observed that the majority of LOMS cohort had a relapsing-onset course of which nearly one-third were exposed to a disease-modifying drug for MS. Among older adults with relapsing-onset MS, we found no significant association between exposure to the most commonly used $\mathrm{DMD}, \operatorname{IFN} \beta$, and progression of disability. To our knowledge, this is the first time a substantial cohort of relapsing-onset 


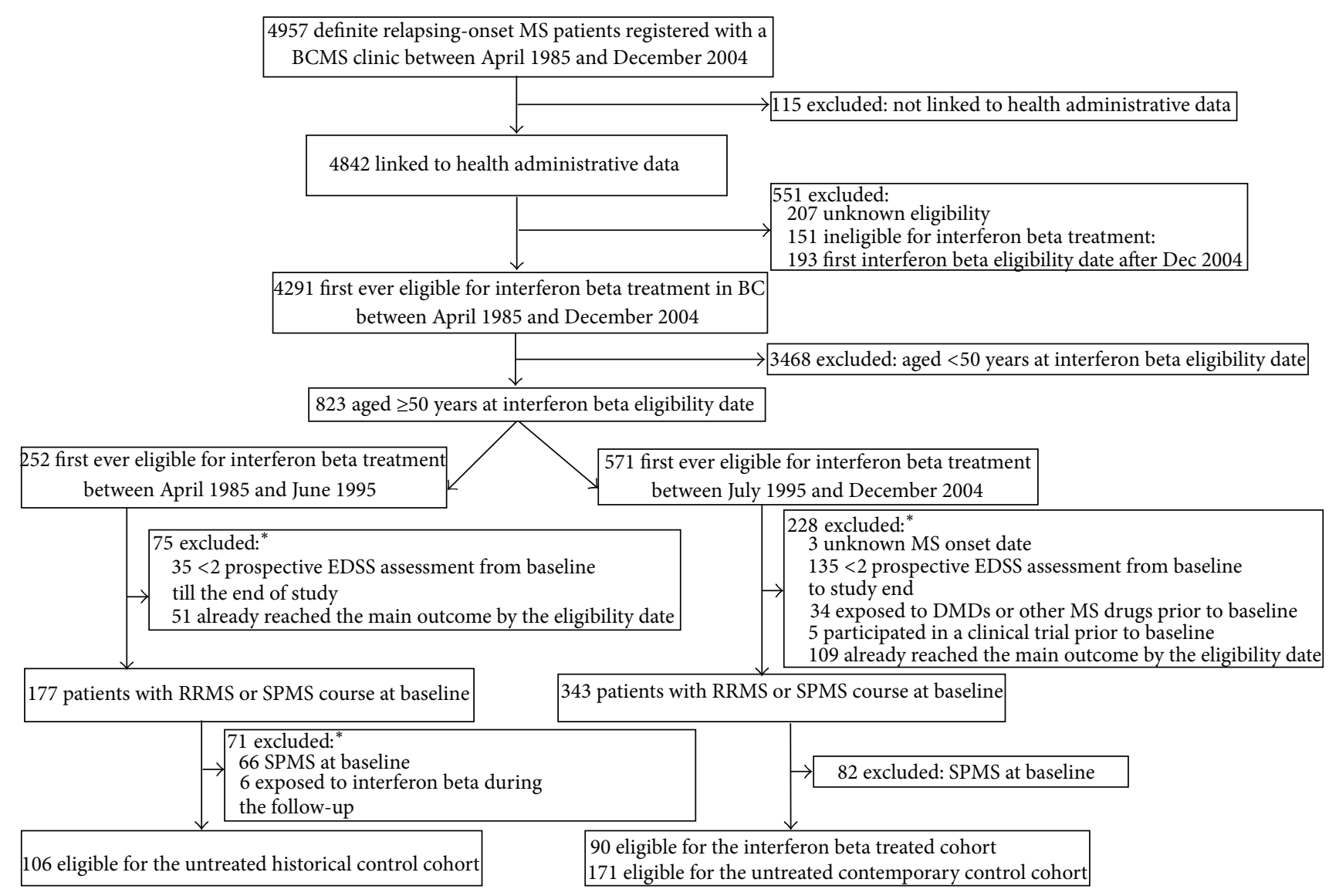

FIGURE 2: Selection of the interferon beta-treated and untreated cohorts aged $\geq 50$ at interferon beta eligibility date. BCMS clinic, British Columbia Multiple Sclerosis clinic; DMD, disease-modifying drug; EDSS, Expanded Disability Status Scale; RRMS, relapsing-remitting multiple sclerosis; and SPMS, secondary progressive multiple sclerosis. ${ }^{*}$ The sum of the individual reasons (numbers) exceeds the total number of patients in some boxes because some patients met more than one condition.

patients with LOMS have been described clinically in the posttreatment era.

Overall, $6 \%$ of our adult cohort fulfilled the criteria for LOMS; others using a similar definition have reported 5\%$12 \%$ affected $[11,31]$. Why there are such differences between studies is not clear, although possible reasons could include study design, cohort size, case ascertainment, life expectancy in the underlying population, and genetic susceptibility. There can be challenges to determining disease course in older adults, including a higher chance of an extended subclinical period or possibly overlooked relapsing-remitting disease activity prior to the overt clinical manifestation of MS [32], such that it is possible that the proportion of LOMS patients with a relapsing-onset course is underestimated. Nonetheless, our observations are of importance given that the only DMDs licensed to date for MS are for patients with a relapsing-onset course.

Our study greatly expands on a previous study examining the natural history of LOMS [10]. By nearly tripling our LOMS cohort size, we were able to more precisely determine the difference in disease progression for relapsing-onset MS patients, with the hazard of reaching EDSS 6 being threefold higher for those with LOMS versus AOMS [10].

We were able to find few other studies describing DMD exposure in LOMS with which to compare our findings [6]. One German study identified 52 patients with LOMS (defined as aged $>50$ at MS diagnosis) and reported a lower rate of exposure to DMDs in LOMS patients compared to those with a younger-onset MS (under 40 years at diagnosis) [6]. Similar to our findings, the most frequently used DMD was IFN $\beta$, with $10 \%$ of those with LOMS exposed versus $54 \%$ in the younger-onset cohort.

The treatment of older adults with MS can be challenging. There is an absence of evidenced-based guidelines; older people in general are often underrepresented in pharmaceutical clinical trials. The pivotal clinical trials of IFN $\beta$ drugs excluded those over the age of 50 or 55 [14-16]. While later clinical trials have increased the upper age limit to 60 or 65 years old [33-35], only one of these focused on IFN $\beta$, with eligibility restricted to those with secondary-progressive MS [35]. Further barriers to including older patients in clinical trials can relate to preexisting comorbidities which may be 
TABLE 2: Characteristics of the treated and untreated (contemporary and historical) cohorts [aim 2]. All comprise relapsing-onset MS patients aged $\geq 50$ at interferon beta eligibility date (baseline).

\begin{tabular}{|c|c|c|c|c|c|}
\hline Characteristics (at baseline ${ }^{*}$, unless otherwise stated) & $\begin{array}{c}\text { Interferon } \\
\text { beta-treated } \\
\text { patients }(n=90)\end{array}$ & $\begin{array}{l}\text { Contemporary } \\
\text { untreated patients } \\
\qquad(n=171)\end{array}$ & $P$ value & $\begin{array}{l}\text { Historical } \\
\text { untreated } \\
\text { patients } \S \\
(n=106)\end{array}$ & $P$ value ${ }^{\|}$ \\
\hline \multicolumn{6}{|l|}{ Sex, $n(\%)$} \\
\hline Male & $17(18.9)$ & $51(29.8)$ & \multirow{2}{*}{$0.06^{9}$} & $24(22.6)$ & \multirow{2}{*}{$0.52^{9}$} \\
\hline Female & $73(81.1)$ & $120(70.2)$ & & $82(77.4)$ & \\
\hline Age at MS onset, years (mean $\pm \mathrm{SD}$ ) & $43.3 \pm 11.6$ & $40.7 \pm 11.1$ & $0.08^{* *}$ & $41.0 \pm 11.7$ & $0.16^{* *}$ \\
\hline \multicolumn{6}{|l|}{$n(\%)$} \\
\hline$<30$ & $13(14.4)$ & $36(21.1)$ & \multirow{4}{*}{$0.31^{g}$} & $20(18.9)$ & \multirow{4}{*}{$0.36^{9}$} \\
\hline $30-<40$ & $19(21.1)$ & $38(22.2)$ & & $22(20.8)$ & \\
\hline $40-<50$ & $27(30.0)$ & $55(32.2)$ & & $39(36.8)$ & \\
\hline$\geq 50$ & $31(34.4)$ & $42(24.6)$ & & $25(23.6)$ & \\
\hline Disease duration, years (mean $\pm \mathrm{SD}$; median [range]) & $\begin{array}{c}10.9 \pm 10.7 \\
7.5[0.03-43.5]\end{array}$ & $\begin{array}{c}14.9 \pm 11.4 \\
13.3[0.2-53.3]\end{array}$ & $0.007^{* *}$ & $\begin{array}{c}15.1 \pm 12.1 \\
12.4[0.3-47.9]\end{array}$ & $0.01^{* *}$ \\
\hline Age, years $($ mean $\pm S D)$ & $54.2 \pm 4.5$ & $55.6 \pm 4.9$ & $0.03^{* *}$ & $56.1 \pm 5.5$ & $0.01^{* *}$ \\
\hline \multicolumn{6}{|l|}{$n(\%)$} \\
\hline $50-<55$ & $65(72.2)$ & $95(55.6)$ & \multirow{3}{*}{$0.03^{9}$} & $55(51.9)$ & \multirow{3}{*}{$0.01^{9}$} \\
\hline $55-<60$ & $16(17.8)$ & $54(31.6)$ & & $28(26.4)$ & \\
\hline$\geq 60$ & $9(10.0)$ & $22(12.9)$ & & $23(21.7)$ & \\
\hline EDSS score (mean \pm SD; median [range]) & $\begin{array}{l}2.5 \pm 1.2 \\
2.5[0-6]\end{array}$ & $\begin{array}{c}2.5 \pm 1.2 \\
2.5[0-6.5]\end{array}$ & $0.99^{\dagger \dagger}$ & $\begin{array}{l}2.4 \pm 1.2 \\
2.5[0-6]\end{array}$ & $0.62^{\dagger \dagger}$ \\
\hline $\begin{array}{l}\text { Annualized relapse rate in the two years prior to } \\
\text { baseline }^{\ddagger \ddagger}(\text { mean } \pm S D)\end{array}$ & $0.6 \pm 0.7$ & $0.4 \pm 0.6$ & $0.006^{* *}$ & $0.4 \pm 0.6$ & $0.08^{* *}$ \\
\hline $\begin{array}{l}\text { Active follow-up time (first to last EDSS assessment), } \\
\text { years (mean } \pm \text { SD) }\end{array}$ & $5.1 \pm 2.7$ & $4.3 \pm 2.7$ & $0.03^{* *}$ & $8.6 \pm 5.1$ & $<0.001^{* *}$ \\
\hline \multicolumn{6}{|l|}{ Charlson comorbidity index ${ }^{\S \S}$ (median [range]) } \\
\hline$n(\%)$ & $0[0-1]$ & $0[0-3]$ & \multirow{3}{*}{$0.59^{9}$} & \multirow{3}{*}{-1\|\|$$} & \\
\hline 0 (no comorbidity) & $85(94.4)$ & $164(95.9)$ & & & \\
\hline$\geq 1$ (at least one comorbid condition) & $5(5.6)$ & $7(4.1)$ & & & \\
\hline \multicolumn{6}{|l|}{ Neighbourhood income quintile ${ }^{\mathbf{g}}, n(\%)$} \\
\hline 1 (lowest income) & $12(13.6)$ & $33(20.2)$ & \multirow{5}{*}{$0.21^{9}$} & \multirow{5}{*}{-1111} & \\
\hline 2 & $11(12.5)$ & $33(20.2)$ & & & \\
\hline 3 & $16(18.2)$ & $28(17.2)$ & & & \\
\hline 4 & $19(21.6)$ & $30(18.4)$ & & & \\
\hline 5 (highest income) & $30(34.1)$ & $39(23.9)$ & & & \\
\hline
\end{tabular}

EDSS, Expanded Disability Status Scale.

${ }^{*}$ Baseline was considered as the first date a patient became eligible for interferon beta treatment (whilst being $>=50$ years old).

${ }^{\dagger}$ Untreated patients who first became eligible for treatment in the "interferon beta era" (whilst being $>=50$ years old).

${ }^{\ddagger}$ Comparison of the interferon beta-treated patients with the contemporary untreated patients.

${ }^{\S}$ Untreated patients who first became eligible for treatment in the "pre-interferon beta era" (whilst being >=50 years old).

"Comparison of the interferon beta-treated patients with the historical untreated patients.

'Pearson's chi-square test.

${ }^{* *}$ Student's $t$-test.

${ }^{\dagger \dagger}$ Mann-Whitney-Wilcoxon test.

${ }^{\#+}$ If this period included MS onset, the first onset attack was not included as a relapse.

${ }^{\$ \varsigma}$ Deyo adaptation of the Charlson comorbidity index, based on hospital admissions or physician visits in the two years prior to baseline and derived from International Classification of Diseases, 9th Revision, Clinical Modification (ICD-9-CM) codes, excluding hemiplegia, paraplegia, and dementia to avoid misclassifying complications of MS as comorbidity. All relevant comorbidities were aggregated into a single variable theoretically ranging from 0 to 33 ; higher scores indicate more comorbidity.

IIII Data incomplete/unavailable.

"Used as a proxy for socioeconomic status. Data were missing for 2 patients in the interferon beta-treated cohort and 8 patients in the contemporary control cohort. 


$\begin{aligned} & \text { Interferon beta-exposed time } \\ & \text { Reference level: unexposed time }\end{aligned}$
$\begin{aligned} & \text { EDSS at baseline } \\ & \text { (per 1 point) }\end{aligned}$
$\begin{aligned} & \text { Disease duration at baseline } \\ & \text { (per 10 years) }\end{aligned}$
$\begin{aligned} & \text { Age at baseline } \\ & \text { (per 10 years) }\end{aligned}$
$\begin{aligned} & \text { Female sex } \\ & \text { Reference level: male }\end{aligned}$

(a) ${ }^{*}$ Interferon beta-exposed patients ${ }^{\dagger}$ versus contemporary controls ${ }^{\ddagger}$

\begin{tabular}{|c|c|}
\hline Interferon beta-exposed time & $\mathrm{HR}(95 \% \mathrm{CI})=0.54(0.20-1.42)$ \\
\hline Reference level: unexposed time & $\Pi К(93 \%(1)=0.34(0.20-1.42)$ \\
\hline $\begin{array}{l}\text { EDSS at baseline } \\
\text { (per } 1 \text { point) }\end{array}$ & $\longrightarrow \quad \mathrm{HR}(95 \% \mathrm{CI})=1.76(1.32-2.35)$ \\
\hline $\begin{array}{l}\text { Disease duration at baseline } \\
\text { (per } 10 \text { years) }\end{array}$ & $\longrightarrow \mathrm{HR}(95 \% \mathrm{CI})=0.89(0.66-1.21)$ \\
\hline $\begin{array}{l}\text { Age at baseline } \\
\text { (per } 10 \text { years) }\end{array}$ & $\mathrm{HR}(95 \% \mathrm{CI})=1.47(0.76-2.85)$ \\
\hline $\begin{array}{l}\text { Female sex } \\
\text { Reference level: male }\end{array}$ & $\longrightarrow \mathrm{HR}(95 \% \mathrm{CI})=0.81(0.35-1.87)$ \\
\hline 0.1 & 10 \\
\hline
\end{tabular}

(b) ${ }^{\S}$ Interferon beta-exposed patients ${ }^{\dagger}$ versus historical controls ${ }^{\|}$

FIGURE 3: Multivariable time-dependent Cox regression analysis of potential factors affecting time to reach confirmed and sustained EDSS 6 for 90 interferon beta-exposed patients versus 171 contemporary controls aged $\geq 50$ at baseline, with interferon beta treatment as a timevarying covariate (a). Results of the same analysis for 90 interferon beta-exposed patients and 106 historical controls (b). ${ }^{*}$ Ten patients who were censored before the earliest event did not contribute to the analysis. ${ }^{\dagger} 266$ person-years of interferon beta exposure and 151 person-years of untreated time ( 92 person-years before and 59 person-years after the initiation of interferon beta treatment). ${ }^{*} 597$ person-years of untreated time. ${ }^{\S}$ Seven patients who were censored before the earliest event did not contribute to the analysis. "694 person-years of untreated time.

more prevalent in these patients. This paucity of evidence highlights the importance of observational studies such as ours.

Information on the impact of DMDs on older MS patients is crucial for a number of reasons. Firstly, older adults with MS are typically treated using therapeutic guidelines originally established for younger adults; however, there is yet no direct evidence to support this practice [32]. Secondly, as aging profoundly affects the pharmacodynamics and pharmacokinetics of drugs as well as the immune system, it is not unreasonable to speculate that immunomodulatory therapies may have a different effect in older MS patients. In addition, the average follow-up time in clinical trials is typically too short (2-3 years) [14-16] to capture the longerterm progression profile of patients. The clinical trial setting is also different from that of the real-world condition in other aspects such as patients' comorbidities and motivation or ability to adhere to medications.

Strengths of our study included a sizable cohort of LOMS patients, inclusion of those with AOMS as a comparison group, substantial follow-up time, use of a conservative definition of the progression outcome, linkage to healthrelated administrative datasets to provide a rich data source, the selection of a comparable baseline (eligibility for IFN $\beta$ treatment) for the treated and control cohorts, consideration of treatment exposure as a time-varying covariate thereby addressing immortal time bias [30] and accounting for the changing treatment status of patients over the follow-up period, and inclusion of both pre- and post-IFN $\beta$ era control cohorts thereby addressing indication bias.

Our study has also some limitations. An estimated 20\% of the MS patients in BC are not captured in the database. Since we included only patients who were attending a BCMS clinic, it is possible that those with LOMS could be overor underrepresented. EDSS, despite being the most widely used scale for measuring MS disability, is weighted toward physical disability and overlooks other relevant aspects of MS such as cognitive dysfunction. LOMS is associated with more rapid progression, increasing the chances of reaching EDSS 6 before first visit in the clinic ("left-censoring"); however we were able to show through a sensitivity analysis that this did not change our main findings. For aim 2, we were not able to examine possible differences between the various IFN $\beta$ products. We were not able to consider biomarkers, imaging data, ethnicity, and the possible effect of change in diagnostic criteria from Poser to McDonald in our study. Our study was not designed to look into the safety profile of IFN $\beta$ drugs which may differ between LOMS and AOMS patients. Our study was also not designed to examine whether the disease course has changed over time (drug treatments 
aside). This was addressed in a previous study, in which we observed MS disease progression to remain relatively stable in BC over two decades [36]. As with any observational study, unmeasured confounding remains possible. Finally, the confidence intervals around our hazard estimates were such that we cannot rule out definitively that the IFN $\beta$ s could delay progression in older adults; there is a real need for further studies in this area.

To the best of our knowledge, this is the largest study of its kind to examine LOMS and the first designed specifically to examine the association between exposure to IFN $\beta$ and disability progression in older MS patients in the realworld setting. Given that the prevalence of older people living with MS will continue to increase as the underlying populations age, there is a real need to better understand the characteristics of these patients and potential response to drug treatments for MS. Ultimately, as many of these patients will be treated with DMDs in clinical practice, there is an urgent need for further studies to develop evidence-based therapeutic guidelines for this special population.

\section{Ethical Approval}

This study was approved by the University of British Columbia's Clinical Research Ethics Board, which includes patient informed consent.

\section{Conflict of Interests}

Afsaneh Shirani has received travel grants to present at and attend conferences from the endMS Research and Training Network (2010, 2011) and the European Committee for Treatment and Research in Multiple Sclerosis (2010, 2011). Yinshan Zhao declares no conflict of interests. Over the past three years, John Petkau has received research funds from Bayer Pharma and travel support, honoraria, consulting fees, or fees for service on Data Safety Monitoring Boards or Steering Committees from Bayer Canada, Bayer Pharma, Bayhill Therapeutics, BTG International, EMD Serono, Merck-Serono, Novartis, the Canadian Study Group on CCSVI, the Myelin Repair Foundation, and Novartis. Over the past year, Paul Gustafson has received consulting fees from AbbVie. Mohammad Ehsanul Karim has had travel and accommodation costs covered from the endMS Research and Training Network $(2011,2012)$ to present at conferences. Charity Evans has received travel grants to present at and attend conferences from the endMS Research and Training Network (2011) and the European Committee for Treatment and Research in Multiple Sclerosis (2011). Elaine Kingwell has had travel and accommodation costs covered to present at and attend conferences from the endMS Research and Training Network (2008, 2011), the International Society for Pharmacoepidemiology (2010), and Bayer Schering Pharma (2010). Mia L. van der Kop declares no conflict of interests. Over the past five years, Joel Oger has received speaker honoraria, consulting fees, and travel grants and/or research grants and/or educational grants from Aventis, Bayer, Biogen-Idec, BioMS, Corixa, Genentech,
Novartis, Serono, Shering, Talecris, and Teva-neurosciences. He received fees for services from Bayer, from Novartis, and from Biogen Idec to serve on advisory committees. Helen Tremlett has received research support from the National Multiple Sclerosis Society, Canadian Institutes of Health Research, and UK MS Trust and speaker honoraria and/or travel expenses to attend conferences from the Consortium of MS Centres, the National MS Society, the University of British Columbia Multiple Sclerosis Research Program, Bayer Pharmaceutical (speaker, 2010, honoraria declined), Teva Pharmaceuticals (speaker 2011), ECTRIMS (2011, 2012, and 2013), UK MS Trust (2011), the Chesapeake Health Education Program, US Veterans Affairs (2012, honorarium declined), Novartis Canada (2012), and Biogen Idec (speaker 2014, honorarium declined). Unless otherwise stated, all speaker honoraria are either donated to an MS charity or to an unrestricted grant for use by her research group.

\section{Authors' Contribution}

Afsaneh Shirani, Yinshan Zhao, and Helen Tremlett designed the study. Afsaneh Shirani managed the data linkage, ensured the data integrity, carried out the statistical analyses, and wrote the first draft of the paper. Helen Tremlett supervised the study, revised the paper, and obtained funding for the study. Yinshan Zhao, Paul Gustafson, John Petkau, and Mohammad Ehsanul Karim provided statistical advice. Afsaneh Shirani, Helen Tremlett, Yinshan Zhao, John Petkau, Paul Gustafson, Mohammad Ehsanul Karim, Charity Evans, Elaine Kingwell, Mia L. van der Kop, and Joel Oger read the paper, provided comments, and approved the final version of the paper.

\section{Acknowledgments}

The authors gratefully acknowledge the BCMS Clinic neurologists who contributed to the study through patient examination and data collection (current members listed here by primary clinic): UBC MS Clinic: A. Traboulsee, M.D., F.R.C.P.C. (UBC Hospital MS Clinic Director and Head of the UBC MS Programs); A-L. Sayao, M.D., F.R.C.P.C.; V. Devonshire, M.D., F.R.C.P.C.; S. Hashimoto, M.D., F.R.C.P.C. (UBC and Victoria MS Clinics); J. Hooge, M.D., F.R.C.P.C. (UBC and Prince George MS Clinics); L. Kastrukoff, M.D., F.R.C.P.C. (UBC and Prince George MS Clinics); and J. Oger, M.D., F.R.C.P.C. Kelowna MS Clinic: D. Adams, M.D., F.R.C.P.C.; D. Craig, M.D., F.R.C.P.C.; and S. Meckling, M.D., F.R.C.P.C. Prince George MS Clinic: L. Daly, M.D., F.R.C.P.C. Victoria MS Clinic: O. Hrebicek, M.D., F.R.C.P.C.; D. Parton, M.D., F.R.C.P.C.; and K Pope, M.D., F.R.C.P.C. The authors also thank P. Rieckmann, M.D. (Sozialstiftung Bamberg Hospital, Germany) for helpful revisions of the original CIHR grant. The views expressed in this paper do not necessarily reflect the views of each individual acknowledged. None have received compensation for their role in the study. The authors would also like to extend their thanks to the UBC MS Clinic nurses and staff and the UBC's Clinical Trials Group. The authors are grateful to Feng Zhu for his help 
with data analysis, Tom Duggan for significant help with data manipulation and conversion, and the Pharmacoepidemiology in MS (PiMS) Research Group for research support. The authors are thankful to Population Data BC for support with data linkage, PharmaNet for drug information, and the BC Ministry of Health for access to health administrative data. Finally, the authors are indebted to all MS patients who participated in this study. Afsaneh Shirani is funded through a Postdoctoral Fellowship from the Multiple Sclerosis Society of Canada and grants from the Canadian Institutes of Health Research (MOP-93646, PI = Helen Tremlett, and DSA-120528, PI: Helen Tremlett) and the National Multiple Sclerosis Society (RG 4202-A-2; PI = Helen Tremlett). Yinshan Zhao received research funding from the Canadian Institutes of Health Research, the Multiple Sclerosis Society of Canada, and the National Multiple Sclerosis Society. John Petkau holds research grants from the Canadian Institutes of Health Research and the Natural Sciences and Engineering Research Council of Canada. Paul Gustafson is supported by the Natural Sciences and Engineering Research Council of Canada. Mohammad Ehsanul Karim is funded through a studentship from the Multiple Sclerosis Society of Canada (2012-2014). Elaine Kingwell is supported by postdoctoral fellowships from the Multiple Sclerosis Society of Canada and the Michael Smith Foundation for Health Research. Mia L. van der Kop is supported by a Canadian Institutes of Health Research Doctoral Foreign Study Award. Joel Oger received support from the Christopher Foundation and the University of British Columbia (UBC). He received fees for service from the Medical Services Commission of British Columbia. Helen Tremlett is funded by the Multiple Sclerosis Society of Canada (Don Paty Career Development Award) and is a Michael Smith Foundation for Health Research Scholar and the Canada Research Chair for Neuroepidemiology and Multiple Sclerosis. She has also received research support from the National Multiple Sclerosis Society, Canadian Institutes of Health Research, and UK Multiple Sclerosis Trust. The study sponsors had no role in the study design, data collection, data analysis, interpretation of results, writing of this paper, or decision to submit. The BCMS database has been funded from various sources (including the above) and also by an unrestricted grant from Dr. Donald Paty and the MS/MRI Research Group.

\section{References}

[1] A. Compston and A. Coles, "Multiple sclerosis," The Lancet, vol. 359, no. 9313, pp. 1221-1231, 2002.

[2] E. Kingwell, M. van der Kop, Y. Zhao et al., "Relative mortality and survival in multiple sclerosis: findings from British Columbia, Canada," Journal of Neurology, Neurosurgery \& Psychiatry, vol. 83, no. 1, pp. 61-66, 2012.

[3] R. A. Marrie, N. Yu, J. Blanchard, S. Leung, and L. Elliott, “The rising prevalence and changing age distribution of multiple sclerosis in Manitoba," Neurology, vol. 74, no. 6, pp. 465-471, 2010.

[4] M. Arias, D. Dapena, S. Arias-Rivas et al., "Late onset multiple sclerosis," Neurologia, vol. 26, no. 5, pp. 291-296, 2011.
[5] M. Etemadifar, S.-H. Abtahi, A. Minagar, M. Akbari, A. Masaeli, and N. Tabrizi, "Lateonset multiple sclerosis in Isfahan, Iran," Archives of Iranian Medicine, vol. 15, no. 10, pp. 596-598, 2012.

[6] B. Kis, B. Rumberg, and P. Berlit, "Clinical characteristics of patients with late-onset multiple sclerosis," Journal of Neurology, vol. 255, no. 5, pp. 697-702, 2008.

[7] O. Lyon-Caen, G. Izquierdo, R. Marteau, F. Lhermitte, P. Castaigne, and J. J. Hauw, "Late onset multiple sclerosis. A clinical study of 16 pathologically proven cases," Acta Neurologica Scandinavica, vol. 72, no. 1, pp. 56-60, 1985.

[8] V. Martinelli, M. Rodegher, L. Moiola, and G. Comi, "Late onset multiple sclerosis: clinical characteristics, prognostic factors and differential diagnosis," Neurological Sciences, vol. 25, supplement 4, pp. S350-S355, 2004.

[9] J. Noseworthy, D. Paty, T. Wonnacott, T. Feasby, and G. Ebers, "Multiple sclerosis after age 50," Neurology, vol. 33, no. 12, pp. 1537-1544, 1983.

[10] H. Tremlett and V. Devonshire, "Is late-onset multiple sclerosis associated with a worse outcome?" Neurology, vol. 67, no. 6, pp. 954-959, 2006.

[11] M. L. Polliack, Y. Barak, and A. Achiron, "Late-onset multiple sclerosis," Journal of the American Geriatrics Society, vol. 49, no. 2, pp. 168-171, 2001.

[12] W. Qiu, J.-S. Wu, A. Castley et al., "Clinical profile and HLADRB1 genotype of late onset multiple sclerosis in Western Australia," Journal of Clinical Neuroscience, vol. 17, no. 8, pp. 1009-1013, 2010.

[13] C. M. Poser, D. W. Paty, and L. Scheinberg, "New diagnostic criteria for multiple sclerosis: guidelines for research protocols," Annals of Neurology, vol. 13, no. 3, pp. 227-231, 1983.

[14] The IFNB Multiple Sclerosis Study Group, "Interferon beta-1b is effective in relapsing-remitting multiple sclerosis. I. Clinical results of a multicenter, randomized, double-blind, placebocontrolled trial," Neurology, vol. 43, no. 4, pp. 655-661, 1993.

[15] "Randomised double-blind placebo-controlled study of interferon beta-1a in relapsing/remitting multiple sclerosis. PRISMS (Prevention of Relapses and Disability by Interferon beta-1a Subcutaneously in Multiple Sclerosis) Study Group," The Lancet, vol. 352, pp. 1498-1504, 1998.

[16] L. D. Jacobs, D. L. Cookfair, R. A. Rudick et al., "Intramuscular interferon beta-1a for disease progression in relapsing multiple sclerosis. The Multiple Sclerosis Collaborative Research Group (MSCRG)," Annals of Neurology, vol. 39, pp. 285-294, 1996.

[17] A. D. Sadovnick, G. C. Ebers, R. W. Wilson, and D. W. Paty, "Life expectancy in patients attending multiple sclerosis clinics," Neurology, vol. 42, no. 5, pp. 991-994, 1992.

[18] V. P. Sweeney, A. D. Sadovnick, and V. Brandejs, "Prevalence of multiple sclerosis in British Columbia," Canadian Journal of Neurological Sciences, vol. 13, no. 1, pp. 47-51, 1986.

[19] A. Shirani, Y. Zhao, M. E. Karim et al., "Association between use of interferon beta and progression of disability in patients with relapsing-remitting multiple sclerosis," Journal of the American Medical Association, vol. 308, no. 3, pp. 247-256, 2012.

[20] H. Tremlett, M. Yousefi, V. Devonshire, P. Rieckmann, and Y. Zhao, "Impact of multiple sclerosis relapses on progression diminishes with time," Neurology, vol. 73, no. 20, pp. 1616-1623, 2009.

[21] H. Tremlett, D. Paty, and V. Devonshire, "Disability progression in multiple sclerosis is slower than previously reported," Neurology, vol. 66, no. 2, pp. 172-177, 2006. 
[22] W. I. McDonald, A. Compston, G. Edan et al., "Recommended diagnostic criteria for multiple sclerosis: guidelines from the International Panel on the Diagnosis of Multiple Sclerosis," Annals of Neurology, vol. 50, no. 1, pp. 121-127, 2001.

[23] F. D. Lublin, S. C. Reingold, and National Multiple Sclerosis Society (USA) Advisory Committee on Clinical Trials of New Agents in Multiple Sclerosis, "Defining the clinical course of multiple sclerosis: results of an international survey," Neurology, vol. 46, no. 4, pp. 907-911, 1996.

[24] J. F. Kurtzke, "Rating neurologic impairment in multiple sclerosis: an expanded disability status scale (EDSS)," Neurology, vol. 33, no. 11, pp. 1444-1452, 1983.

[25] BC Ministry of Health, Data Extract, PharmaNet. BC Ministry of Health, Data Stewardship Committee, 2010, http://www .popdata.bc.ca/data.

[26] British Columbia Ministry of Health, Discharge Abstract Database (Hospital Separations), Data Extract, MOH, Population Data BC, 2010, http://www.popdata.bc.ca/data.

[27] British Columbia Ministry of Health [creator], Medical Services Plan (MSP) Payment Information File, Population Data BC, 2010, http://www.popdata.bc.ca/data.

[28] British Columbia Ministry of Health, Consolidation File (MSP Registration \& Premium Billing), Population Data BC, Data Extract. MOH, 2009, http://www.popdata.bc.ca/data.

[29] Multiple Sclerosis Society of Canada, "Treatments-modifying the disease course," http://mssociety.ca/en/treatments/modify .htm.

[30] S. Suissa, "Immortal time bias in observational studies of drug effects," Pharmacoepidemiology and Drug Safety, vol. 16, no. 3, pp. 241-249, 2007.

[31] J. G. Phadke, "Clinical aspects of multiple sclerosis in north-east Scotland with particular reference to its course and prognosis," Brain, vol. 113, no. 6, pp. 1597-1628, 1990.

[32] A. Awad and O. Sütve, "Multiple sclerosis in the elderly patient," Drugs and Aging, vol. 27, no. 4, pp. 283-294, 2010.

[33] L. Kappos, J. Antel, G. Comi et al., "Oral fingolimod (FTY720) for relapsing multiple sclerosis," The New England Journal of Medicine, vol. 355, no. 11, pp. 1124-1140, 2006.

[34] D. H. Miller, O. A. Khan, W. A. Sheremata et al., "A controlled trial of natalizumab for relapsing multiple sclerosis," The New England Journal of Medicine, vol. 348, no. 1, pp. 15-23, 2003.

[35] H. Panitch, A. Miller, D. Paty, and B. Weinshenker, "Interferon beta-1b in secondary progressive MS: results from a 3-year controlled study," Neurology, vol. 63, no. 10, pp. 1788-1795, 2004.

[36] A. Shirani, Y. Zhao, E. Kingwell, P. Rieckmann, and H. Tremlett, "Temporal trends of disability progression in multiple sclerosis: findings from British Columbia, Canada (1975-2009)," Multiple Sclerosis, vol. 18, no. 4, pp. 442-450, 2012. 


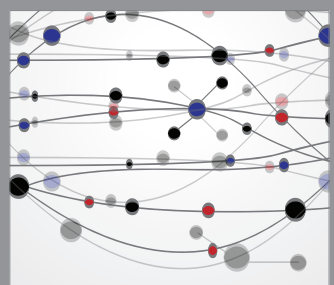

The Scientific World Journal
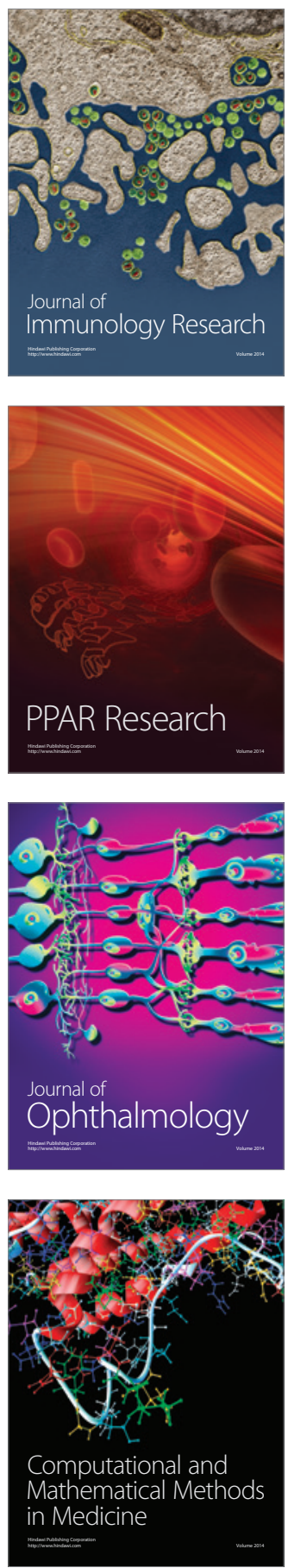

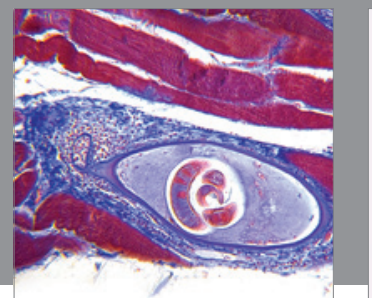

Gastroenterology

Research and Practice
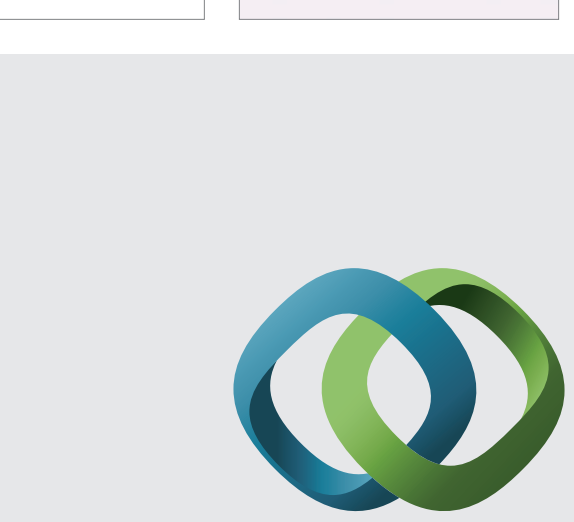

\section{Hindawi}

Submit your manuscripts at

http://www.hindawi.com
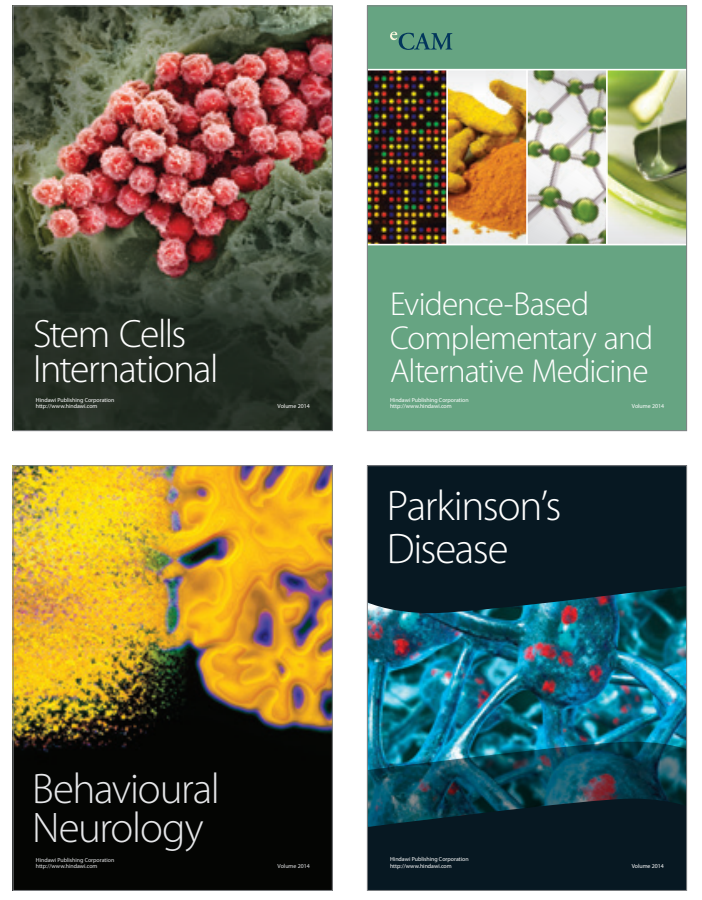
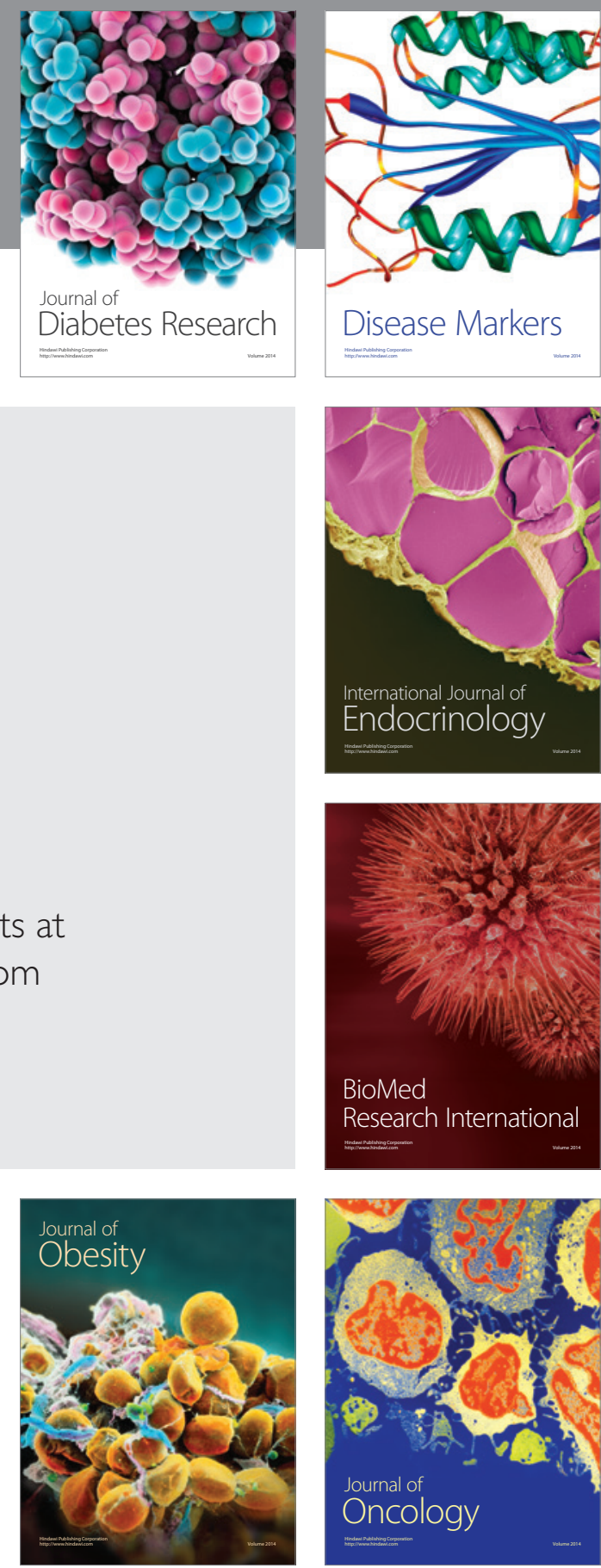

Disease Markers
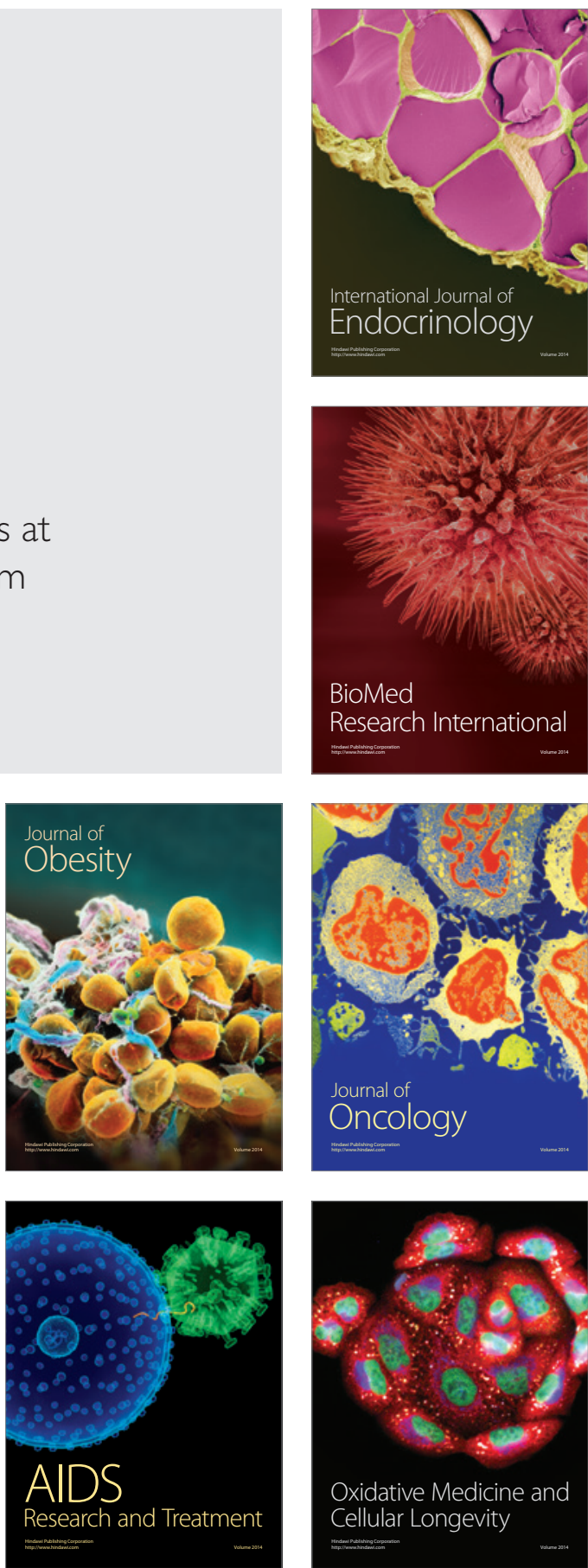